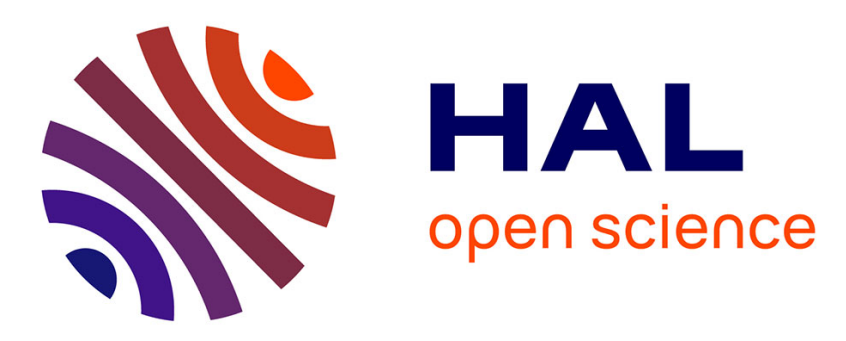

\title{
Rheology of white paints: How Van Gogh achieved his famous impasto
}

J. Salvant Plisson, Laurence de Viguerie, L. Tahroucht, M. Menu, G. Ducouret

\section{To cite this version:}

J. Salvant Plisson, Laurence de Viguerie, L. Tahroucht, M. Menu, G. Ducouret. Rheology of white paints: How Van Gogh achieved his famous impasto. Colloids and Surfaces A: Physicochemical and Engineering Aspects, 2014, 458, pp.134 - 141. 10.1016/j.colsurfa.2014.02.055 . hal-01516143

\section{HAL Id: hal-01516143 https://hal.sorbonne-universite.fr/hal-01516143}

Submitted on 28 Apr 2017

HAL is a multi-disciplinary open access archive for the deposit and dissemination of scientific research documents, whether they are published or not. The documents may come from teaching and research institutions in France or abroad, or from public or private research centers.
L'archive ouverte pluridisciplinaire HAL, est destinée au dépôt et à la diffusion de documents scientifiques de niveau recherche, publiés ou non, émanant des établissements d'enseignement et de recherche français ou étrangers, des laboratoires publics ou privés. 


\title{
Rheology of white paints: How Van Gogh achieved his famous impasto
}

\author{
J. Salvant Plisson ${ }^{\mathrm{a}}$, L. de Viguerie ${ }^{\mathrm{b}, \mathrm{c}, *}$, L. Tahroucht $^{\mathrm{d}}$, M. Menu $^{\mathrm{a}, \mathrm{g}}$, G. Ducouret $^{\mathrm{d}, \mathrm{e}, \mathrm{f}}$ \\ a Centre de Recherche et de Restauration des Musées de France, C2RMF, Palais du Louvre, 14 Quai François Mitterrand, Paris F-75001, France \\ b UPMC Univ Paris 06, UMR 8220, Laboratoire d'archéologie moléculaire et structurale, LAMS, Paris F-75005, France \\ c CNRS, UMR 8220, LAMS, F-75005 Paris, France \\ d UPMC Univ Paris 06, UMR 7615, Laboratoire de Sciences et Ingénierie de la Matière Molle (SIMM), Paris F-75005, France \\ e CNRS, UMR 7615, SIMM, Paris F-75005 France \\ ${ }^{\mathrm{f}}$ ESPCI, UMR 7615, SIMM, Paris F-75005 France \\ ${ }^{\mathrm{g}}$ Institut de Recherche de Chimie Paris, IRCP, 11 rue Pierre et Marie Curie, Paris F-75006, France
}

\section{H I G H L I G H T S}

- The rheological properties of 19 th century white paint formulations have been compared.

- Lead and zinc white paints both exhibit viscoelastic properties, characteristic of paste suspensions.

- Yield stress and elastic moduli are strongly dependant on the nature, treatment and proportion of oil.

- At all studied concentrations, yield stress and elastic modulus at $1 \mathrm{~Hz}$ are higher for zinc white paints.

- This zinc white property can explain its specific use by V. Van Gogh, to create impasto.

\section{A R T I C L E I N F O}

\section{Article history:}

Received 4 October 2013

Received in revised form 5 February 2014

Accepted 8 February 2014

Available online 12 March 2014

\section{Keywords:}

Paint reconstructions

Zinc and lead white

Impasto

Vincent Van Gogh

Rheology

Oil paints
G R A P H I C A L A B S T R A C T
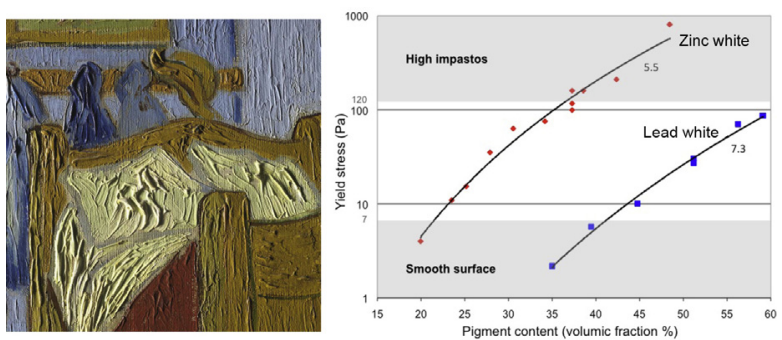

\begin{abstract}
A B S T R A C T
Paints based on white pigments are the basic materials found in ground layers of ready-made canvases as well as in painting layers mixed with other colours. It is surprising that Vincent Van Gogh, whose unique style is world famous, resorted to not one but two types of white paints. Indeed, Van Gogh often used both lead white and zinc white in the very same painting, contrasting then with the majority of his contemporaries who have only used the traditional lead white. To trace the evolution of his painting technique and to respond to the issues of authentication, dating and preservation raised by his artwork, it is essential to have a good knowledge of the painting materials he used and how he used them.

This paper describes the reconstructions of 19th century white paint formulations and their rheological characterization in order to compare their flow properties: by adjusting them, different paint finishes from smooth surfaces to high impastos can be produced. We define a general procedure for paint rheology characterization, useful for old recipes reconstructions in the field of conservation science. Both lead white and zinc white based paints exhibit a similar rheological behaviour, with a fluid to solid transition, and variations of their properties such as yield stress and elastic moduli, depending on their formulation (oil nature, content, and treatment). An explanation on the specific use of zinc white can be proposed as it allows higher impastos than a lead white paint containing the same oil content.
\end{abstract}

(c) 2014 Elsevier B.V. All rights reserved.

\footnotetext{
* Corresponding author at: CNRS, UPMC, UMR 8220, LAMS, F-75005 Paris, France. Tel.: +331 44278226.

E-mail address: laurence.de_viguerie@upmc.fr (L. de Viguerie).
} 


\section{Introduction}

Paint based on white pigments is one of the most commonly used by artists: indeed, white paints, often mixed with small amount of coloured paints, constitute the basis of many painting layers. For example, if one has a look to the orders of oil paint tubes by Vincent Van Gogh (1853-1890), precisely described in his letters, it appears clearly that he used a very large amount of white oil paint tubes to produce his artworks known for their bright colours [1]. This was also confirmed by different studies performed in the past: analyses have shown that coloured painting layers are commonly made of white pigments with a small amount of coloured pigment [2]. At the end of the 19th century, two types of pigments were available to produce white paints: lead white (generally mixture of lead carbonates, $\mathrm{PbCO}_{3} / 2 \mathrm{PbCO}_{3} \cdot \mathrm{Pb}(\mathrm{OH})_{2}$ ) and zinc white (zinc oxide, $\mathrm{ZnO}$ ). Since Antiquity, lead white has been one of the only white pigment used in oil painting as it possesses excellent properties. It was produced industrially during the 19th century by using the Dutch Stack process, consisting in exposing metallic lead strips to vinegar fumes (acetic acid) and manure in a close space for several months. Lead white remained the only white pigment used in oil painting until lead white toxicity became an important concern [3]. This is why, from the end of the 18th century, there was a crucial need to develop an alternative white pigment for oil paint. Zinc white appeared to be the best alternative. After improving the manufacturing, zinc white became available on an industrial scale around the middle of the 19th century [4].

Zinc white remained of very little use to artists from the second half of the 19th century, such as the Impressionists, who usually chose to use the traditional lead white, probably because zinc white was said to be slower to dry and had poor covering power,(i.e. the ability of a paint to obscure the surface upon which it is applied) [5]. Unlike his contemporaries, Van Gogh used both zinc white and lead white paints to produce artworks: indeed, orders of large amount of oil paint tubes of blanc d'argent (referring to lead white) and blanc de zinc (referring to zinc white) are regularly mentioned in his letters [1]. Additionally, Van Gogh often used both zinc white and lead white paints simultaneously in the very same painting according to previous research [6-10]. Despite complaining in many letters about the slow drying of zinc white [11], Van Gogh indicated that it had other advantages [12] that he did not specify. One can wonder which specific advantages Van Gogh found in each type of white paint and how he was using them in his artworks.

As can be found in ancient catalogues from paint suppliers ( $L e$ Père Tanguy catalogue dating from ca. 1888 to 1890 or 1876 Lefranc catalogue) [5,9], lead and zinc white oil paint tubes were the same price. Some major differences between lead white and zinc white paint properties have already been described in literature. Lead white paint has a shorter drying time and a better covering power, whereas zinc white give better colours in mixture with pigments [4-6,13,14]. Among appearance and drying properties, the paint texture and consistency are also crucial, particularly in the case of Van Gogh, well-known for his high impastos, resulting from the application of paint in thick layers to produce a textured surface (Fig. 1). Indeed, artists by adjusting paint consistencies and textures can produce very different effects, ranging from very smooth surface to very high impastos.

Based on reconstructions of 19th century oil paints, we investigated the use of white paints by Vincent Van Gogh in relation to their consistency and texture. To get a better understanding on the different use of lead and zinc white paints in Van Gogh's artworks, their rheological properties have been characterized. A discussion is then proposed on the levelling properties of paint materials applied to Van Gogh's paint layers.

\section{Materials and methods}

\subsection{Paint samples reconstructions}

Reconstructions of 19th century oil paint were prepared according to previous investigations and to the specific oil absorption value of each pigment investigated $[2-4,15,16]$. Three different pigments were used to prepare the formulations: zinc white, lead white and cobalt blue (suppliers indicated in Table 1). They were first imaged by SEM (see Supporting Information, S1). Paint made of $37 \% \mathrm{vol}$ of zinc white were prepared, ground with different oils (nature, treatment and supplier in Table 1) in order to compare their rheological properties and choose an appropriate oil for further measurements. We used linseed and poppy oils similar to oils that were commonly employed during the 19 th century. The two linseed oils from Laverdure are both cold pressed but their treatments are different: oil "cat. B", which has been chosen for further experiments, has been refined whereas the oil "cat. A" has been purified.

Paints with linseed oil ("cat. B") and different proportions of one or two white pigment(s) were prepared and tested according to the proportions listed in Table 2 . The paints based on respectively zinc white/lead white/cobalt blue are noted $\mathrm{ZW} / \mathrm{LW} / \mathrm{CB}$ together with numbers indicating the pigment volumic content (\%vol). As an example, the paint named ZW30-CB10 contains 30\%vol of zinc white, $10 \%$ vol of cobalt blue and thus $60 \% \mathrm{vol}$ of oil. For the mixtures of two pigments, the oil content is fixed at $60 \% \mathrm{vol}$, which has been estimated as the usual concentration in Van Gogh white paints estimated by a combination of PIXE and RBS techniques [17].

$10-20 \mathrm{~g}$ of paint was prepared from raw pigments and oil at the different compositions. First the appropriate amount of oil was added to the pigment and mixed with the palette knife. The mixture was then roughly divided into three parts and each third was ground under the muller on a glass plate during 120 s (Fig. 1). The three parts were then mixed together to homogenize the whole and divided again by third and ground for $40 \mathrm{~s}$.

Some formulations were unstable over few days and released oil. Moreover, it was observed that some lead white based formulations, when allowed to rest, get spontaneously more fluent within a short time. Such a behaviour was not detected for zinc white and cobalt blue paints. This change of consistency could be explained by the improvement of the oil-wetting of lead white pigments and/or by the oil diffusion with time in the aggregates that remain poorly dispersed, leading progressively to a better lubrication of pigment

Table 1

Different oils and pigments tested. The oils viscosity was measured and estimated at c.a. $5 \times 10^{-2}$ Pa.s.

\begin{tabular}{|c|c|c|c|c|}
\hline & Nature & Supplier & Density & Preparation and treatment \\
\hline \multirow[t]{3}{*}{ Oil } & Linseed & Laverdure & & Cat. A: cold-pressed, purified \\
\hline & Linseed & Laverdure & & Cat. B: cold-pressed, refined \\
\hline & Poppy & Kremer & & Refined \\
\hline \multirow[t]{3}{*}{ Pigment } & Zinc White & Kremer (No. 46,300) & 5.6 & \\
\hline & Lead white (mainly hydrocerussite) & Natural Pigments & 6.5 & Dutch stack process \\
\hline & Cobalt Blue & Kremer (No. 45,710) & 4.3 & \\
\hline
\end{tabular}



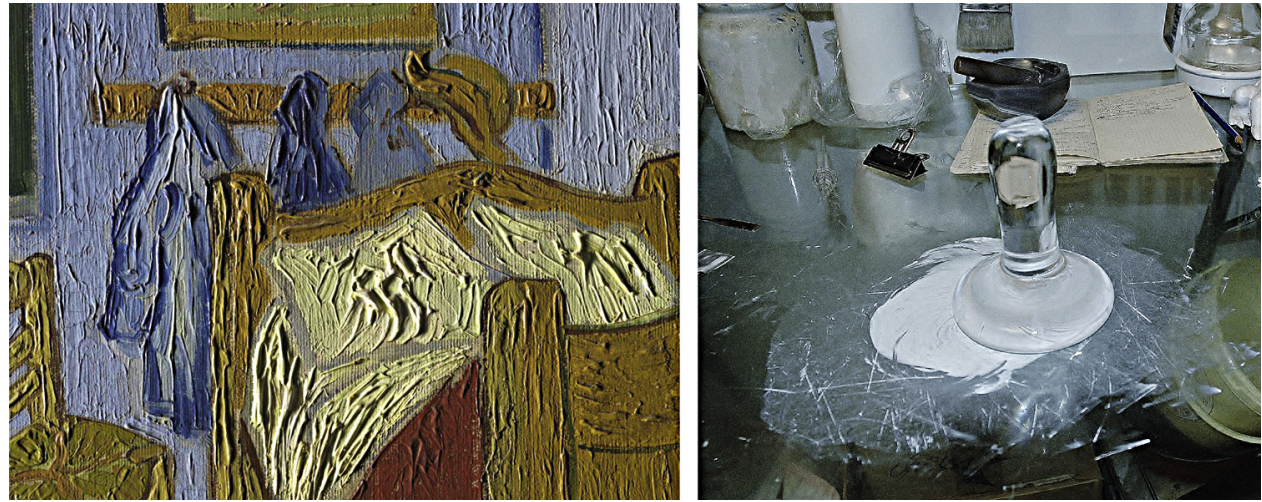

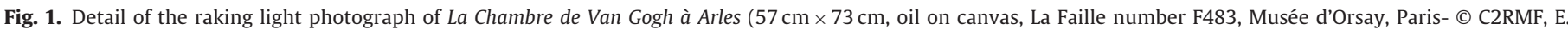

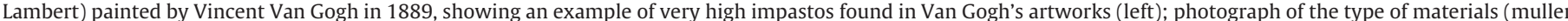
and glass plate) used for the preparation of reconstructed oil paint samples from oil and raw pigment powder (right).

particles. To limit these effects, the paints were prepared and their rheological properties investigated on the same day.

\subsection{Rheology}

The rheological measurements were performed at $25^{\circ} \mathrm{C}$. Yield stress and dynamical properties were measured using a strain controlled rheometer TA instruments ARES (LS1) equipped with a serrated plate/plate geometry (diameter: 25 or $40 \mathrm{~mm}$ ) or a rough cone and plate geometry (diameter: $50 \mathrm{~mm}$, angle: 0.04 radian, gap: $0.045 \mathrm{~mm}$ ). The stress controlled rheometer Haake RS600 equipped with a rough cone and plate geometry (diameter: $35 \mathrm{~mm}$; angle: 0.04 radian), or a serrated plate/plate (diameter: $35 \mathrm{~mm}$ ) was also used when required. All the geometries are stainless steel except the titanium cone of the ARES. The gap for the plate geometries was fixed at values in between 0.5 and $2.1 \mathrm{~mm}$ depending on the amount of paint added. Each measurement was repeated twice to check the reproducibility. Another sample with the same composition, prepared in the same conditions, was also analyzed and its properties compared to the first one.

For all the formulations, the following dynamical measurements have been performed:

- strain sweep tests in the linear regime (from $0.01 \%$ strain to the end of the linear viscoelastic plateau), at $\omega=1 \mathrm{~Hz}$, in order to determine the extent of the linear regime,

- frequency sweep tests, from 0.1 to $100 \mathrm{rads}^{-1}$ at constant strain in the linear regime,

- strain sweep tests, at $\omega=1 \mathrm{~Hz}$, for strain further the linear regime.

The yield stress has been evaluated using two different methods: creep test and flow measurements. As a general procedure only the flow measurement method has been used; the creep measurements are reported in the Supporting Information. The flow measurements (shear rate sweep test) were measured from 0.001 to $200 \mathrm{~s}^{-1}$ (waiting time: $30 \mathrm{~s}$, measurement time: $20 \mathrm{~s}$ ). In some cases, the flow measurement was performed with both increasing and decreasing the shear rate.

As ageing features are expected in concentrated suspensions, we tried to estimate the paint ageing (definition in Section 3.1.2). The sample was submitted to a mechanical fluidification in order to put the system in a fluid state independent from its history. The protocol of fluidification was empirically determined: the samples were submitted to an oscillatory strain of amplitude $100 \%$, at a frequency of $1 \mathrm{~Hz}$ during $100 \mathrm{~s}$ in order to get reproducible mechanical responses. After the protocol of fluidification at $t=0$, the sample evolved spontaneously during a waiting time $t_{w}$. At $t=t_{w}$, a small strain of $0.2 \%$ (in the linear regime) was applied and the relaxation of the stress was measured. This measurement was performed for different waiting times: $t_{w}=10,100,1000$ and $10000 \mathrm{~s}$.

\subsection{Roughness measurements}

To investigate the topography and particularly the surface roughness of a painting, we used the Micromesure from STIL, a non-contact extended field confocal imaging system. It consists in motorized x, y, z stages and a CHR 150 confocal sensor. It is controlled with the Surface map software. The data are processed with the Mountains Map Universal software. Optical pen of $3000 \mu \mathrm{m}$ was used to scan an area of $25 \mathrm{~mm} \times 25 \mathrm{~mm}$ at $100 \mathrm{~Hz}$ with a step of $50 \mu \mathrm{m}$ in $x$ and $y$ directions.

\section{Results}

\subsection{Rheological behaviour of paint samples}

\subsubsection{General description}

All the paints studied exhibit viscoelastic properties, characteristic of pastes suspensions (Fig. 2).

Table 2

Composition of paints with linseed oil (in \%vol), from Laverdure. The volume fraction was calculated from the weight introduced and the density of the materials.

\begin{tabular}{|c|c|c|c|c|c|}
\hline Paints & Reference name & Zinc white & Lead white & Cobalt blue & Linseed oil \\
\hline Zinc white (ZW) & ZW & $19.9-48.5$ & 0 & 0 & $52.5-80.1$ \\
\hline Lead white (LW) & LW & 0 & $35-59.1$ & 0 & $40.9-65$ \\
\hline Zinc white and cobalt & ZW30-CB10 & 30 & & 10 & 60 \\
\hline \multirow[t]{2}{*}{ blue $(\mathrm{ZW}-\mathrm{CB})$} & ZW35-CB5 & 35 & & 5 & 60 \\
\hline & ZW39-CB1 & 39 & & 1 & 60 \\
\hline Lead white and cobalt & LW30-CB10 & & 30 & 10 & 60 \\
\hline \multirow[t]{2}{*}{ blue $(\mathrm{LW}-\mathrm{CB})$} & LW35-CB5 & & 35 & 5 & 60 \\
\hline & LW39-CB1 & & 39 & 1 & 60 \\
\hline Zinc white and lead & ZW25-LW75 & 8.5 & 25.5 & & 60 \\
\hline \multirow{2}{*}{ white (ZW-LW) } & ZW50-LW50 & 17 & 17 & & 60 \\
\hline & ZW75-LW25 & 25.5 & 8.5 & & 60 \\
\hline
\end{tabular}




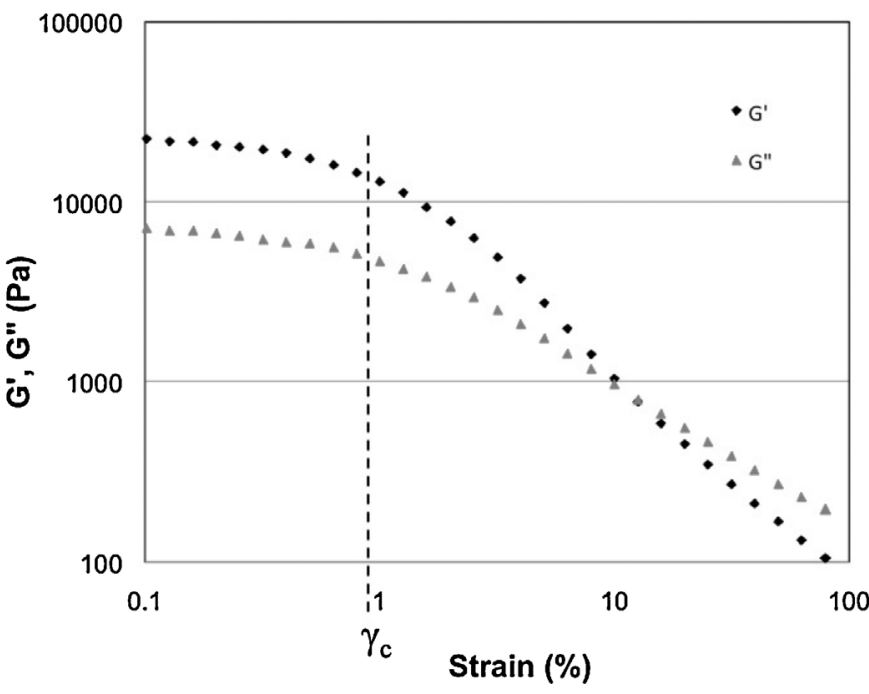

Fig. 2. Strain sweep test for a paint sample (zinc white ground in linseed oil with a volumic pigment content of $37 \% \mathrm{vol}$ ) showing the evolution of the elastic modulus $G^{\prime}$ and the viscous modulus $\mathrm{G}^{\prime \prime}$ in function of the strain at constant frequency $(1 \mathrm{~Hz})$. The paints exhibit a viscoelastic behaviour.

At low strains, the elastic modulus $G^{\prime}$ is higher than the viscous modulus $G^{\prime \prime}$ and there is not much evolution of both moduli: the system is elastic on all this strain range that is called the linear viscoelastic region. Beyond a critical strain $\gamma_{c}$, related to the dynamic yield stress $\tau_{c}$, the elastic modulus decreases and the system becomes viscous $\left(G^{\prime \prime}>G^{\prime}\right)$, the paint flows. This type of behaviour, characteristic of suspensions pastes, has been observed for example in silica suspensions and microgel suspensions [18].

Flow measurements (Fig. 3) during the ramp-down are almost identical to the ones during the ramp-up until the yield stress is reached when the shear rate sweep is slow enough to perform measurements at the equilibrium of the sample (total time measurement of about $80 \mathrm{~min}$; Fig. 3a): a good reversibility is observed for the measurements between the ramp-up and the ramp-down. The system has restructured and exhibits again its elastic properties. It is interesting to note that stress measurements during the ramp-down are slightly lower than the ones during the ramp-up, as it has also been observed for other systems, such as granular pastes [19]. The evolution of the stress in function of shear rate follows the Herschel-Bulkley model [20,21]. On the other hand, when measurements are performed with a fast shear rate sweep (total time measurements of about $6 \mathrm{~min}$; Fig. $3 \mathrm{~b}$ ), a phenomenon of hysteresis is observed, showing a slight thixotropic behaviour [22] of the paint.

As a consequence of this time-dependant behaviour, several parameters, such as the time between sample preparation and measurements and the waiting time between measurements were identified as having an influence on the measured rheological behaviour. By controlling those parameters, we observed a good reproducibility between the measurements with a dispersion of about $20 \%$ for all the formulations (except linseed oil A).

\subsubsection{Ageing measurements}

To explore the history-dependent effect in rheological paint measurements, we performed ageing measurements based on the experimental procedure described by Derec et al. [23] for concentrated colloidal suspensions (see experimental conditions above). Indeed, in those systems rheological ageing has been observed [23-28]: the response to a mechanical perturbation depends on the time elapsed after preparation [25]. At short times, an elastic response of the sample, an increase of the stress, is observed as a consequence of the $0.2 \%$ constant step strain perturbation the sample is submitted to (Fig. 4). After $0.05 \mathrm{~s}$, the stress is relaxing. The stress relaxation profile is the same whatever the waiting time $t_{w}$ is, but the relaxation is slower when the waiting time increases. The elastic modulus, calculated from the maximum stress value (which is much lower than the yield stress) increases together with higher waiting time (Fig. 4). This is due to the fact that there was longer time for the material to restructure with higher waiting time. Higher elastic modulus values highlight a more important reorganization of the material.

\subsection{Influence of paint formulation}

\subsubsection{Influence of the nature of oil}

We compared the rheological behaviour of paint formulations containing $37 \% \mathrm{vol}$ of zinc white, ground in different oils following the same procedure. The yield stress and the elastic modulus $G^{\prime}$ measured at $1 \mathrm{~Hz}$ for the different formulations are indicated in Table 3. Whereas the initial viscosities of the oils alone are quite close (c.a. $5 \times 10^{-2} \mathrm{Pas}$ ) the rheological properties of the paint obtained appeared to be quite different. During the paint preparation step, this was already visible as pigments were dispersed very easily in some oils and with greater difficulty in others. The two oils from Laverdure only differ from the treatment, although the oil absorption value and the needed grinding time to obtain a homogeneous formulation are different for both. We chose to keep constant those parameters in this experiment but there is no doubt a painter would slightly modify these for proper use if necessary.
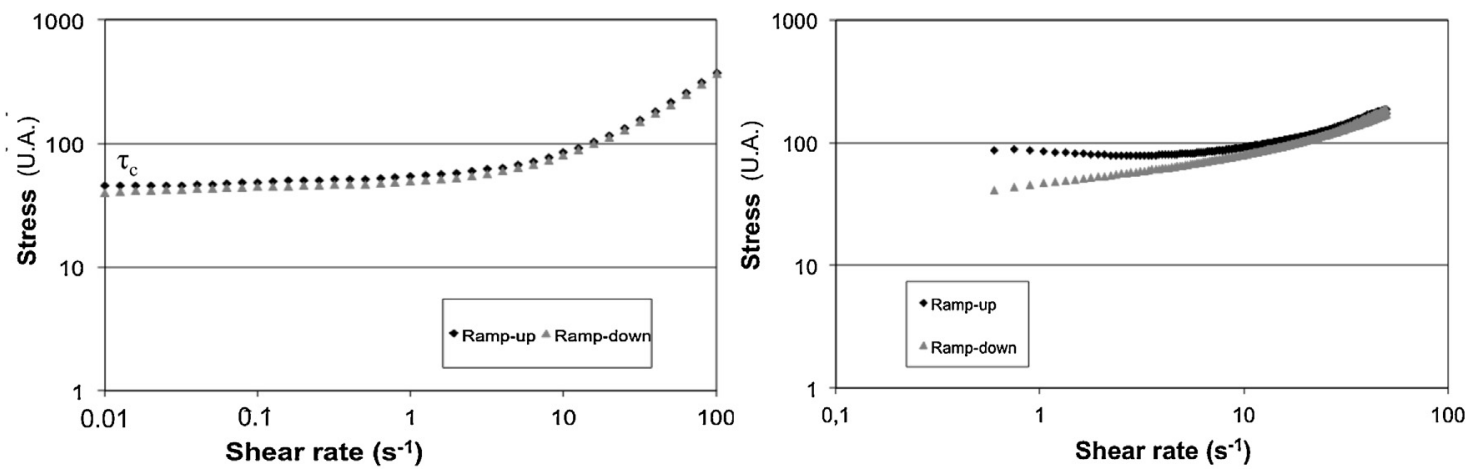

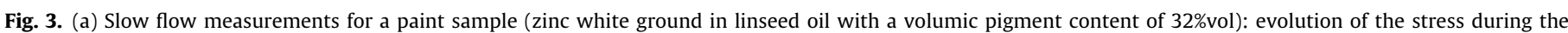

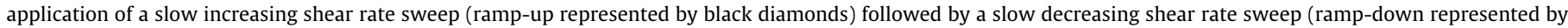

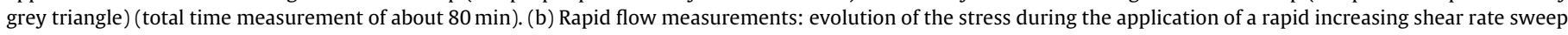
(ramp-up, black diamonds) followed by a slow decreasing shear rate sweep (ramp-down, grey triangles) (total time measurement of about 6 min). 

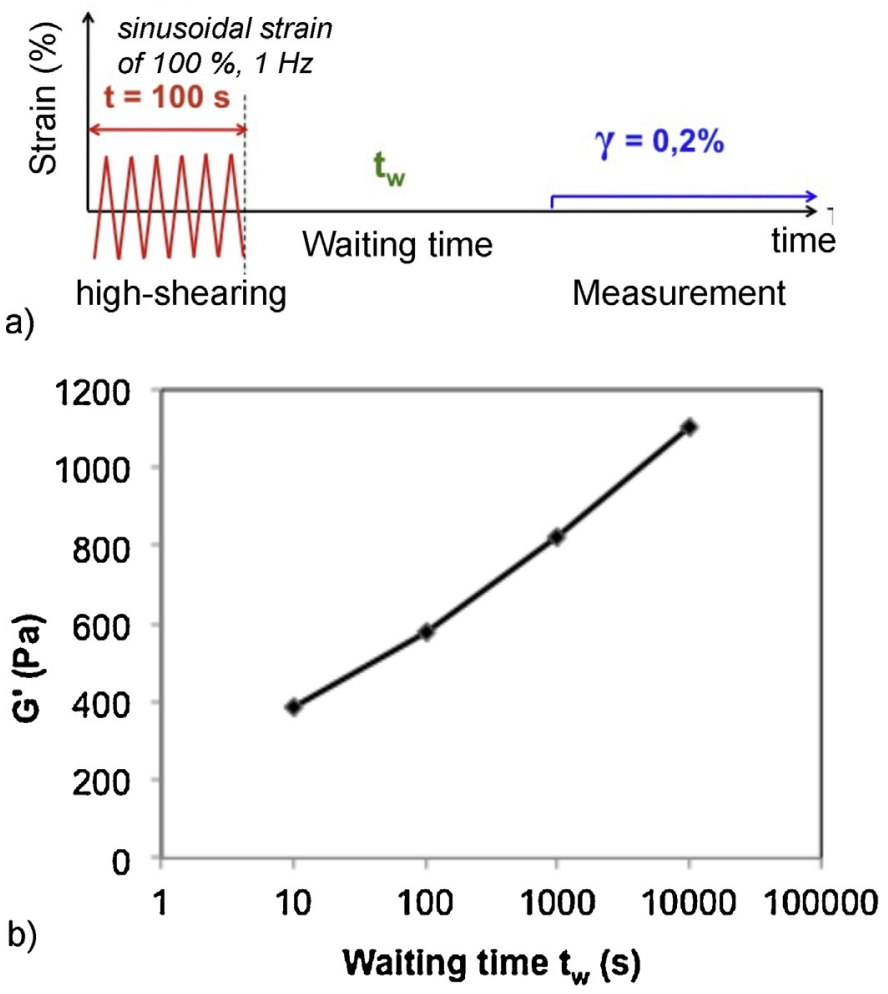

Fig. 4. Ageing measurements on paint samples: (a) schematic representation of the experimental procedure the sample was submitted to; (b) evolution of the elastic modulus (maximum stress value divided by the strain, i.e. $0.2 \%$ ), in function of the waiting time $t_{w}$.

Table 3

Elastic Modulus $G^{\prime}$, measured at $1 \mathrm{~Hz}$ and yield stress, depending on the oil in paints containing $37 \% \mathrm{vol}$ of zinc white.

\begin{tabular}{lcl}
\hline & $G^{\prime}(1 \mathrm{~Hz})$ in Pa & Yield stress in Pa \\
\hline Linseed oil, cat A, Laverdure & 108,000 & 430 \\
Linseed oil, cat B, Laverdure & 15,300 & 155 \\
Poppy oil refined, Kremer & 52,000 & 540 \\
\hline
\end{tabular}

Not only the nature of oil but also the processing method has a strong impact on the paint rheology. Indeed for refined linseed oil, the measured $G^{\prime}$ at $1 \mathrm{~Hz}$ is c.a. $15,000 \mathrm{~Pa}$, whereas it is respectively of 52,000 Pa for refined poppy oil, and of 108,000 Pa for purified linseed oil (Table 3). This strong influence of the oil nature and treatment has already been observed in the literature [15,29,30]: it is particularly true in the case of lead white and much less important for pigments such as vine black or umber. Depending on its nature and processing method, the oil composition is different and thus its reactivity and pigment affinity can be modified. Except otherwise stated, we used the refined linseed oil from Laverdure ("cat. B"), as it allowed good reproducibility of our measurements.

\subsubsection{Influence of pigment type and concentration}

We studied the evolution of the yield stress and the elastic modulus $G^{\prime}$ at $1 \mathrm{~Hz}$ in function of the pigment concentration for lead white and zinc white oil paints. All the possible range of pigment concentration providing a suitable paste to paint was explored. Fig. 5 shows the evolution of the yield stress in function of the volume fraction of pigment for the two types of paints. The volume fractions of pigments were calculated from the weight fractions of pigments used in the formulation, the pigment densities indicated by the suppliers (Table 1 ) and a density of $0.93 \mathrm{~g} / \mathrm{cm}^{3}$ for linseed oil as mentioned in the literature [31].

At all studied concentrations, the yield stress and the elastic modulus at $1 \mathrm{~Hz}$ are much higher in the case of zinc white based paints, compared to lead white. For each type of pigments, they increase with the volume fraction of pigments, which is fully coherent. The yield stress and the elastic modulus at $1 \mathrm{~Hz}$ vary in function of the volume fraction of the pigment $(\phi)$ with power laws $\left(\tau_{c} \sim \phi^{\mathrm{B}}\right.$ and $G^{\prime} \sim \phi^{\mathrm{B}^{\prime}}$ with $\mathrm{B}$ and $\mathrm{B}^{\prime}$ positive constants). A good correlation is observed between the evolution of the elastic modulus at $1 \mathrm{~Hz}$ and the one of the yield stress in function of the pigment concentrations. For zinc white paints, the two exponents of the power laws representing the elastic modulus and the yield stress variation in function of the volume fraction of pigment are very similar (respectively of 5.6 and 5.5). This is fully consistent with what has been described by Mahaut et al. [32] for colloidal suspension systems. However, this is not what was observed for lead white paints, where the exponents are 4.1 and 7.3 for the elastic modulus and the yield stress respectively. One explanation of this difference can rely
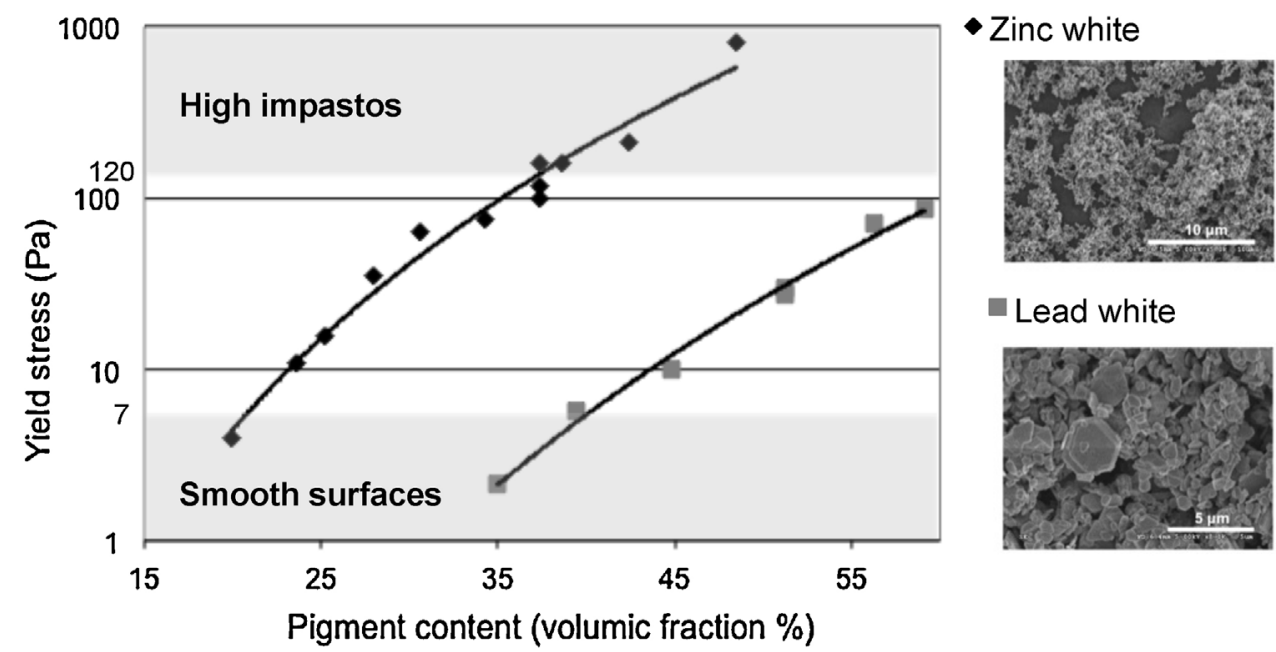

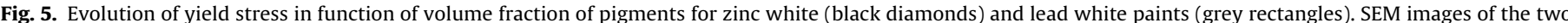

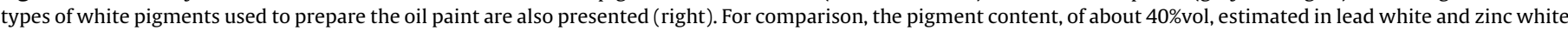

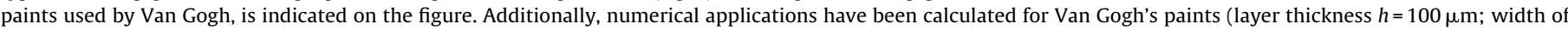

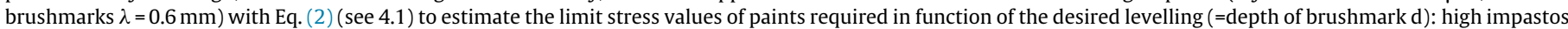

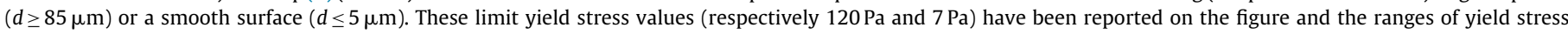
corresponding to high impastos and smooth surfaces are indicated as grey areas. 


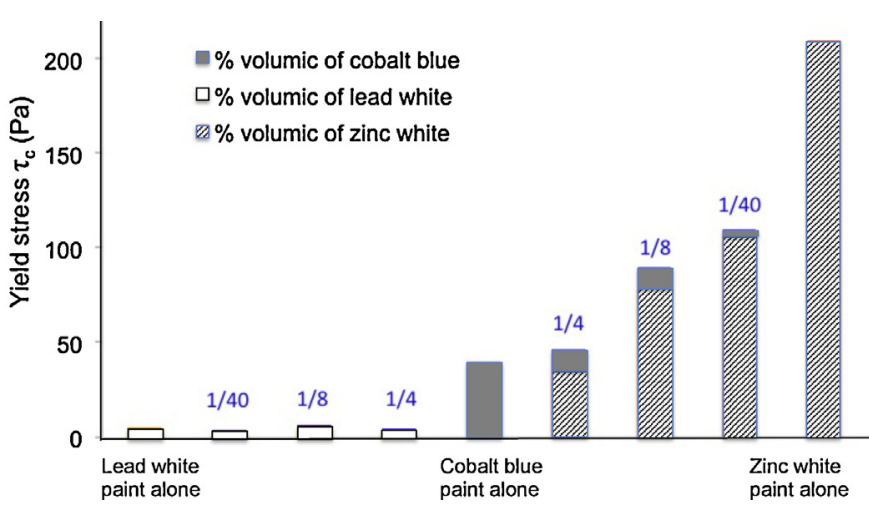

Fig. 6. Comparison of the yield stress of oil paint mixtures made from $40 \%$ vol pig ment and $60 \%$ vol linseed oil. Each rectangle represents a paint formulation and its height represents the measured yield stress (in Pa) of the formulation. Formulations made of one pigment alone or of the mixture of a white pigment (lead white or zinc white) with cobalt blue have been studied. The following colour code has been used: white for lead white, grey for cobalt blue and striped for zinc white paint. For paints composed of two pigments, the proportion of grey indicates the volumic proportion of cobalt blue in the total volumic content of pigment of $40 \%(1 / 4,1 / 8$ or $1 / 40$ in volume).

on the peculiar shape of the lead white grains, which make them more difficult to disperse in oil. Indeed the SEM observations of the pigments (see Figs. S1 and 5) show that the used lead white was mainly constituted of hexagonal platelet shaped pigments of about 1-2 $\mu \mathrm{m}$ (hydrocerussite grains), whereas the zinc white was composed of more isotropic grains of smaller size $(<1 \mu \mathrm{m})$. The precise influence of the size and shape of the grains, as well as the chemical interactions between oil and pigments, should be investigated further to conclude whether it can explain the rheological differences between lead and zinc white.

\subsubsection{Influence of pigment mixtures}

We studied the influence of the addition of a third pigment in white paints in order to compare the two types of paints: the studied formulations are based on Vincent Van Gogh's coloured painted layers, where white paints are often used in mixture with a small amount of coloured pigment. The influence of the addition of cobalt blue, a blue pigment often used by Van Gogh, on the rheological properties of white paints was investigated. For the paint mixture of zinc white and cobalt blue (total volume fraction of pigment $40 \%$ ), the addition of a small amount of cobalt blue ( $1 \%$ in volume of the total pigment content) produces an important decrease of the yield stress of the paint (110 Pa) compare to the zinc white paint without other pigments (210 Pa) (Fig. 6). The same evolution is observed for the elastic modulus at $1 \mathrm{~Hz}$ : it is important for zinc white paint, but it rapidly decreases when zinc white is mixed with another pigment. Dissimilarly for the lead white based paints, the addition of cobalt blue does not modify significantly the yield stress and the elastic modulus, even when higher amount of cobalt blue is added. The measured yield stress for lead white paint mixtures remains of the same order of magnitude (around 4-7 Pa) whatever the cobalt blue content; the small variations observed are related to the measurement precision.

All these results point out that the phenomenon providing zinc white paints with an important yield stress and elastic modulus is not preserved when zinc white is mixed with another pigment, even when present in minor amount. It suggests that there is a specific interaction between zinc white and oil that plays a main role on the observed rheological behaviour and provides an higher yield stress and elastic modulus to zinc white paints compared to lead white paints at the same volume pigment content.

\section{Application to artists' paints properties and finish}

\subsection{Levelling of paints}

The rheological characterization of paints can be interpreted in relation with the "finish" of the artwork, that is to say the final visual surface aspect of the painting after drying, and thus can help for reverse engineering of masters recipes. The levelling properties are of particular interest here. Surface forces tend to produce flow of the applied film, smoothing the surface irregularities incidental to application by brushing. Many publications [33] propose that yield behaviour affect levelling process. First it causes levelling to cease when the surface tension stress becomes less than the effective yield stress; and it influences the low shear viscosity, through remnants of the structure responsible for the yield behaviour. Smith et al. derived the equations of plane strain for an elastic solid in 1961 to describe this levelling process [34]. Orchard extended it in terms of Fourier series, for any rough surface. The general expression of the roughness amplitude is then [35]:

$a=a_{0} \exp \left[-\frac{\pi \gamma}{\lambda} f\left(\frac{2 \pi h}{\lambda}\right) \int \frac{1}{\eta} d t\right]$,

with $\lambda$ the wavelength, $\mathrm{h}$ the layer thickness, $\gamma$ and $\eta$, respectively the film surface tension and its viscosity.

This equation can be simplified considering a viscosity and a surface tension independent of time, and with approximations for small or big thicknesses: one can then calculate the maximum shear stress (leading to the yield value). Neglecting gravity compared to the surface tension, and considering small amplitude disturbances $(d \ll \lambda)$, and small film thickness $(h \ll \lambda)$ [33,34], the authors obtain the following expression for the maximum shear stress $f$ :

$f=\frac{4 \pi^{3} \gamma d h}{\lambda^{3}}$

with $d$ the depth, $\lambda$ the brushstrokes average wavelength and $h$ the layer thickness, according to Fig. 7a.f indicates the paint yield value inducing brushstrokes of such shape.

Later many theoretical or experimental further developments attempted to take into account the stress or shear rate history, the effects of thin film geometry, the evaporation during drying, possible thixotropy [36], effect of elasticity, etc... . In 1992, Kristiansen, showed from an experimental study, that the Orchard Eq. (2) is still accurate when $a / h<0.2$. Eley's review recalls the different publications on the estimation of levelling in paint industry [37]; however his conclusion underlines the failure in obtaining a general predictive method useful in paint industry.

In our case, the aim is to compare different paint formulations used for art in terms of levelling ability. We neglect gravity, and evaporation effect is not relevant for oil paint. Moreover we neglect the viscosity time dependence of our paint: it obviously exists, but can be neglected regarding the average values and as a matter of comparison. We can thus use the Orchard formula as an estimation of the average brush mark height depending on the paint yield stress. We focus on layers and paints that respect the limit conditions: small amplitude disturbances $(d \ll \lambda)$, and small film thickness $(d \ll \lambda)$. As an example, for $h=5 \mu \mathrm{m}, \lambda=0.5 \mathrm{~mm}$, $\gamma=25 \mathrm{mN} \mathrm{m}^{-1}$ (at the interface oil-air) and $d=1 \mu \mathrm{m}$ which is the minimum value for a visible brush mark, a value of $f=0.12 \mathrm{~Pa}$ is obtained. This is even too low to be measured in standard measurements (using our equipment). This condition of perfect levelling is obtained in the case of low viscosity glazes, closed to Newtonian fluids, used by Renaissance painters such as Van Eyck or Leonardo da Vinci. They were used as thin layers superimposed to achieve a perfect finish [38]. Later painters used brushstrokes to express feelings, movement, or give a sensation of volume. 
a)
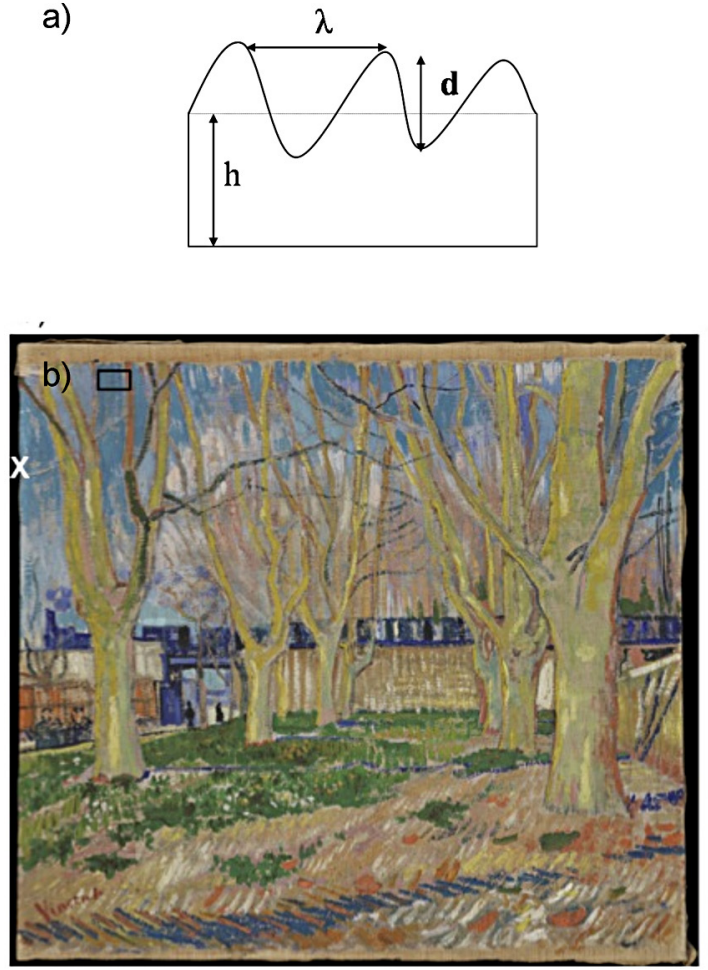

c)
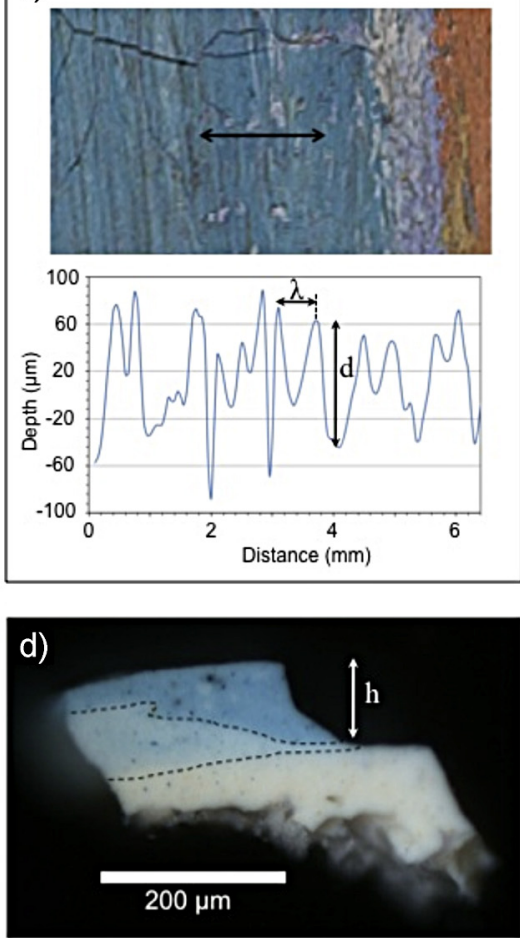

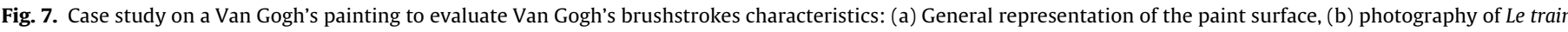

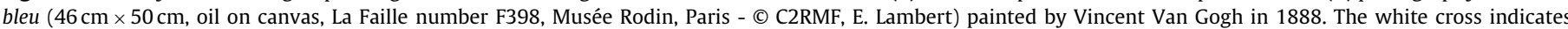

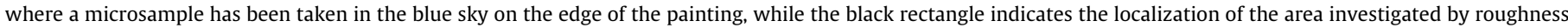

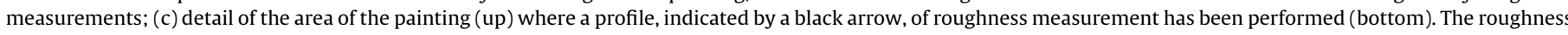

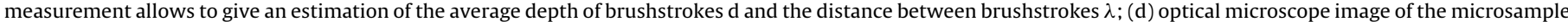
taken from the blue sky of Le train bleu and prepared as cross-section where the thickness layer h can be evaluated.

\subsection{Van Gogh's use of white paints}

The rheological measurements have shown that if we compare lead white and zinc white paint at $40 \% \mathrm{vol}$ for example (Fig. 5), the yield stress is about 30 times higher for zinc white than for lead white. Zinc white paint is pasty while lead white paint is fluid: zinc white is more suitable to leave brushmarks visible. This is true for white paint layers but also for pigment mixtures in zinc white and lead white based paint.

To evaluate the obtained brushstrokes, we applied Eq. (2) to the paintings "Le train Bleu" produced by Van Gogh in 1888 while staying in the South of France, in Arles (Fig. 7b). Microtopography on the blue colour of the sky (Fig. 7c) indicated an average depth of brushstrokes of $85 \mu \mathrm{m}$ and the distance between brushstrokes around $0.6 \mathrm{~mm}$. The thickness layers were estimated on a large panel of cross-sections taken from Van Gogh's paintings [17] ranging between 20 and $600 \mu \mathrm{m}$ with an average value at about $100 \mu \mathrm{m}$. This thickness is very similar to the one observed in the cross-sections taken from the sky of Le train bleu (Fig. 7d). We can estimate the yield stress inducing such brushmarks: about $120 \mathrm{~Pa}$. However we are close to the limit conditions of the used approximation: small amplitude disturbances $(d<\lambda)$, and small film thickness $(h<\lambda)$. This exact value has to be taken cautiously: it just gives an estimation and allows to better figure out the behaviour of the paint used by V. Van Gogh in this painting.

This study provides new insights on the motivation of Van Gogh to use two different white pigments. In addition to better optical properties in pigment mixtures, zinc white would more easily allow high impastos to be achieved. This explanation would be consistent with the trend observed on a small corpus of 37 cross sections made from microsamples from 16 Van Gogh's paintings dated between
1886 and 1890: on this corpus zinc white is used more often on the surface layers than lead white [2]. Moreover, the use of lead white rather than zinc white in the underlayers would be consistent with lead white ability of drying faster and its high covering power.

\section{Conclusion}

The rheological behaviour of two white pigments based paints has been investigated, according to reconstructions of 19th century artistic formulations. As particulate pastes, their macroscopic rheology is dominated by the existence of a fluid-to-solid transition. At stresses above the so-called yield stress, the materials flow like viscous liquids, whereas they behave like solids at lower stresses with properties that evolve slowly with time. We could underline the effect of paint formulation (pigment content and nature but also oil treatment) on the rheological properties of zinc and lead white. The differences between both pigments are related to their chemical composition inducing different interactions with oil, as well as to their specific size and shape of grains. The lead white grains are indeed particularly anisotropic ("needle"-shaped for cerussite grains or hexagonal flat grains in the case of hydrocerussite), contrary to the more isotropic grains of zinc white.

The main difficulty of these experiments lay in the nature of the samples: they exhibit a complex behaviour with possible time dependent effects. Moreover the data interpretation is also complicated. It is not possible to predict behaviour of paint formulations after application with precision: only an estimation of their levelling properties can be provided. This question remains a big issue in the paint industry as many other parameters than the yield stress value would have to be considered especially in the case of time dependent fluids. 
This rheological study gives us new clues to understand the artist's practice. Zinc white induces higher yield stress and elastic properties than lead white-based paints. This can partly explain its specific use by Van Gogh. Many studies in art conservation science deal with old recipes reconstructions including a qualitative description of the paint texture. To improve the discussions and exchanges between conservators, conservation scientists, rheologists and industrial paint experts, the paint flow properties have been described more precisely.

\section{Acknowledgements}

The authors are pleased to acknowledge Freddy Martin for the SEM observations of pigments and Mathieu Caillau for the rheological measurements performed during his internship. We also express our gratitude to Dr. Guillaume Ovarlez for his careful reading of the manuscript and his comments and to Thierry Moutard Martin for his expertise on paint preparations and many fruitful discussions. We are also grateful to Nadine Lehni, chief conservator of the Musée Rodin, Paris, for allowing us to study the painting Le Train Bleu. Lastly, we acknowledge Dr. Marc Walton, senior scientist at NU-ACCESS, for being our «native English speaker» to help making the manuscript smoother.

\section{Appendix A. Supplementary data}

Supplementary data associated with this article can be found, in the online version, at http://dx.doi.org/10.1016/j.colsurfa. 2014.02.055.

\section{References}

[1] V. Van Gogh, Vincent Van Gogh, Les Lettres, Edition critique complète illustrée, Acte Sud - Van Gogh Museum - Huygens Institute, 2009 http://vangoghletters.org/vg/letters.html

[2] J. Salvant, Caractérisation des propriétés physico-chimiques des matériaux de peinture employés par Van Gogh: les peintures blanches, Paris 6 University, in: Ph.D. thesis), 2012, pp. 126-128.

[3] R.J. Gettens, H. Kühn, W.T. Chase, Lead white, in: A. Roy (Ed.), Artists' Pigments: A Handbook of their History and Characteristics, vol. 2, National Gallery of Art, Washington, DC, 1993, pp. 67-81.

[4] H. Kühn, Zinc white, in: R.L. Feller (Ed.), Artists' pigments: A Handbook of their history and Characteristics, vol. 1, National Gallery of Art, Washington, DC, 1986, pp. 169-186.

[5] D. Bomford, J. Kirby, J. Leighton, A. Roy, Art in the Making: Impressionism, National Gallery Publications, London, 1990.

[6] H. Travers Newton, E. Farrell, R. Newman, in: Vincent Van Gogh's Self-Portrait Dedicated to Paul Gaugu An Historical Technical Study, Harvard University Press, 1984.

[7] C. Peres, M. Hoyle, L. van Tilborgh, in: A Closer Look: Technical and art-historical studies on works by Van Gogh and Gauguin, Cahier Vincent 3, Zwolle, 1991.

[8] E. Hendriks, Van Gogh's working practice: a technical study (Ph.D. thesis), in: E. Hendriks, L. van Tilborgh (Eds.), New Views on Van Gogh's Development in Antwerp and Paris: An integrated Art Historical and Technical study of his paintings in the Van Gogh Museum, Amsterdam University, 2006, pp. 99-191 (Ph.D. thesis).

[9] E. Hendriks et, M. Geldof, Van Gogh's working practice: a technical study, in: E. Hendriks, L. van Tilborgh (Eds.), Vincent Van Gogh Paintings, Volume 2: Antwerp and Paris, 1885-1888, Van Gogh Museum, Amsterdam and Waanders Publishers, Zwolle, 2011, pp. 90-143.

[10] Marino, Paints Quantified: Image Analytical Studies of Preparatory Grounds used by Van Gogh, in: Ph.D. thesis), Amsterdam University, 2006.

[11] V. Van Gogh, Letters 591, 631 and 636, in: Vincent Van Gogh. Les Lettres, Edition critique complète illustrée, Acte Sud - Van Gogh Museum - Huygens Institute, 2009.
[12] V. Van Gogh, Letter 631, in: Vincent Van Gogh. Les Lettres, Edition critique complète illustrée, Acte Sud - Van Gogh Museum - Huygens Institute, 2009.

[13] T.J. Ellis, Sketching from nature, in: A Handbook for Students and Amateurs, Macmillan \& Co., Londres, 1887

[14] F. Kerkdijk (Ed.), Les matériaux pour artiste-peintres, fourth, Aperldoorn, Hollande, 1954.

[15] L. Carlyle, with contributions by M. Witlox, K. Pilz, M. Chavannes and B. Baade, HART Report 2002-2005, De Mayerne Programme, Netherlands Organisation for Scientific Research (NWO), 2005 (unpublished, but available for consultation at Tate, Netherlands Cultural Heritage Agency (RCE), Netherlands Institute for Atomic and Molecular Physics (AMOLF), Canadian Conservation Institute $(\mathrm{CCI})$ ).

[16] L. Carlyle, Historically Accurate Reconstructions of Oil Painters' Materials: an overview of the Hart Project 2002-2005, in: J.J. Boon, S.B. Ferreira (Ed) (Eds.), Reporting Highlights of the De Mayerne Programme N.W.O., The Hague, 2006 pp. 63-76.

[17] J. Salvant, Caractérisation des propriétés physico-chimiques des matériaux de peinture employés par Van Gogh: les peintures blanches, in: Ph.D. thesis), Paris 6 University, 2012, pp. 134-141.

[18] (a) O. Neel, G. Ducouret, F. Lafuma, Fluidification of concentrate aqueous colloidal silica suspensions by adsorption of low-molecular-weight poly(ethylene oxide), J. Colloid Interface Sci. 230 (2) (2000) 244-253;

(b) R. Borrega, Suspensions de microgels polyélectrolytes: propriétés phyicochimiques, rhéologie, écoulement, Ph. D. thesis) (2000).

[19] G. Ovarlez, Introduction to the rheometry of complex suspensions, in: N. Roussel (Ed.), Understanding the Rheology of Concrete, Woodhead Publishing, Cambridge, 2012.

[20] G. Couarraze, J.L. Grossiord, in: Initiation à la rhéologie, Tec \& Doc, Lavoisier, Paris, 2000.

[21] J. Mewis, N.J. Wagner, in: Colloidal Suspension Rheology, Cambridge University Press, 2013.

[22] I. Deschères, Les peintures en phase aqueuse, in: C. Daniel, C. Pichot (Eds.), Les latex synthétiques, Lavoisier, Paris, 2006, pp. 589-612.

[23] C. Derec, A. Ajdari, G. Ducouret, F. Lequeux, Rheological characterization of aging in a concentrated colloidal suspension, C. R. Acad. Sci. - Series IV - Physics 18 (2000) 1115-1119.

[24] R. Borrega, Suspensions de microgels polyélectrolytes: propriétés physicochimiques, rhéologie, écoulement, Paris 6 University, in: Ph.D. thesis), 2000.

[25] C. Derec, G. Ducouret, A. Ajdari, F. Lequeux, Aging and non linear rheology in suspensions of polyethylene oxide-protected silica particules, Phys. Rev. E 67 (2003), 061403-1-061403-9.

[26] M. Cloitre, R. Borrega, L. Leibler, Rheological aging and rejuvenation in microgel pastes, Phys. Rev. Lett. 85 (2000) 4819-4822.

[27] C. Derec, A. Ajdari, F. Lequeux, Rheology and aging: a simple approach, Eur. Phys. J. E: Soft Matter Biol. Phys. 4 (3) (2001) 355-361.

[28] B.M. Erwin, D. Vlassopoulos, M. Gauthier, M. Cloitre, Unique slow dynamics and aging phenomena in soft glassy suspensions of multiarm star polymers, Phys. Rev. E 83 (2011) 061402.

[29] J.D. van den Berg, N.D. Vermist, L. Carlyle, M. Holcapek, J.J. Boon, Effects of traditional processing methods of linseed oil on the composition of its triacylglycerols, J. Sep. Sci. 27 (2004) 181-199.

[30] I. Bonaduce, L. Carlyle, M.P. Colombini, C. Duce, C. Ferrari, E. Ribechini, P. Selleri, M.R. Tiné, A multi-analytical approach to studying binding media in oil paintings, J. Therm. Anal. Calorim. 107 (2012) 1055-1066.

[31] R.J. Gettens, G.L. Stout, Painting Materials, A Short Encyclopedia, Dover Publications, New York, 1996

[32] F. Mahaut, X. Chateau, P. Coussot, G. Ovarlez, Yield stress and elastic modulus of suspensions of noncolloidal particles in yield stress fluids, J. Rheol. 52 (1) (2008) 287-313.

[33] (a) T.R. Bullett, Rheology in painting, Rheol Acta 4 (4) (1965) 258-260; (b) E.K. Fischer, Rheological properties of commercial paints, J. Coll. Sci. 5 (3) (1950) 271-281.

[34] N.D.P. Smith, S.E. Orchard, A.J. Rhind-Tutt, The physics of brushmarks, J. Oil Col. Chem. Assoc. 44 (1961) 618-633.

[35] S.E. Orchard, On surface levelling in viscous liquids and gels, Appl. Sci. Res. A $11(1961) 451-464$

[36] O. Cohu, A. Magnin, The leveling of thixotropic coatings, Prog. Org. Coat. 28 (2) (1996) 89-96.

[37] R.R. Eley, Applied rheology in protective and decorative coatings industry, Rheology Rev. (2005) 173-240.

[38] L. de Viguerie, G. Ducouret, T. Moutard-Martin, F. Lequeux, Ph. Walter, Historical evolution of oil painting media: a rheological study, C. R. Phys. 10 (7) (2009) 612-621. 